\title{
VEINTITRÉS AÑOS DE TRIBUNAL CONSTITUCIONAL
}

ANTONIO TORRES DEL MORAL

Catedrático de Derecho Constitucional

UNED 


\section{SUMARIO}

1. Creación y naturalezza del tribunal Constitucional. 2. Composición, ORGANIZACIÓN INTERNA Y FUNCIONAMIENTO. 3. COMPETENCIAS. 4. CONTROL DE LA CONSTITUCIONALIDAD DE LAS LEYES Y DE LAS NORMAS DEL MISMO RANGO. 4.1. Normas impugnables. 4.2. Bloque y canon de la constitucionalidad. 4.3. Tipos de control de constitucionalidad. 4.4. Recurso de inconstitucionalidad. 4.5. Cuestión de inconstitucionalidad. 4.6. Control de constitucionalidad de los tratados internacionales. 4.7. La sentencia en el proceso de inconstitucionalidad. 5. CONFLICTOS DE COMPETENCIAS. 6. IMPUGNACIÓN POR EL GOBIERNO DE LAS DISPOSICIONES SIN FUERZA DE LEYY RESOLUCIONES DE LAS COMUNIDADES AUtÓnomas. 7. CONFLiCtOS ENTRE ÓRganos constitucionales. 8. QuaEstiones disputatae. 8.7. Sobre los actos con fuerza de ley susceptibles de recurso. 8.2. Control de constitucionalidad de los tratados. 8.3. Relación de la Constitución española con el Derecho comunitario y con los tratados internacionales. 8.4. La autocuestión de inconstitucionalidad. 8.5. Carácter constitutivo o declarativo de las sentencias. Sentencias interpretativas. 8.6. Conflictos de competencias. 8.7. Relación de órganos legitimados para promover un conflicto entre órganos constitucionales. 9. BALANCE. 9.1. Labor delTribunal en relación con los derechos fundamentales y con el Estado autonómico. 9.2. Composición del Tribunal. 9.3. Diferencias entre las salas. 9.4. Control de constitucionalidad de los proyectos de reforma constitucional. 


\title{
VEINTITRÉS AÑOS DE TRIBUNAL CONSTITUCIONAL
}

\author{
POR \\ ANTONIOTORRES DEL MORAL \\ Catedrático de Derecho Constitucional \\ UNED
}

\section{CREACIÓNY NATURALEZA DEL TRIBUNAL CONSTITUCIONAL}

\begin{abstract}
El único antecedente español de jurisdicción constitucional es el Tribunal de Garantías Constitucionales que instauró la Constitución de 1931 y que tuvo una azarosa vida, como todo en aquel régimen. Hubo también dos intentos fallidos. Uno fue el Proyecto de Constitución Federal de 1873, que confería el control de constitucionalidad de las leyes alTribunal Supremo. Otro, el del Anteproyecto constitucional primorriverista de 1929, que preveía su atribución al Consejo del Reino, órgano novedoso en tal texto. Este segundo modelo fue recogido por el régimen franquista, que atribuía la resolución de los recursos de contrafuero, que así se llamaban, al Jefe del Estado a propuesta del Consejo del Reino.

El título IX de la Constitución, que regula el Tribunal Constitucional, fue aprobado casi por unanimidad y sin dilatado debate. Había cierto consenso, acaso como reacción frente al régimen anterior, acerca de la necesidad de culminar el Ordenamiento constitucional con un órgano garante de la supremacía de la propia Constitución y de los derechos fundamentales, además de que ésa era la opción apropiada
\end{abstract}


para un Estado compuesto, como la Constitución habilitaba en su artículo $2 .^{\circ}$ y regulaba en el título VIII. La Ley Orgánica de esteTribunal fue aprobada por el procedimiento de urgencia un año después de promulgada la Constitución (1979) y unos meses más tarde, ya en 1980, fue constituido el Tribunal. Todo ello habla, como hemos dicho, del consenso constitucional en torno a esta materia.

El que se optara por un órgano especial, separado del Poder Judicial, para residenciar en él la jurisdicción constitucional se debió también, como ha anotado P. PérezTremps, a un soterrado rechazo de algunas fuerzas políticas frente a un Poder Judicial proveniente del régimen franquista y con escasa conciencia constitucional en 1978. Por eso también, que el Tribunal Constitucional sea el último órgano constitucional regulado por la norma suprema, seguramente quiso resaltar ese carácter de órgano especial garante del orden instaurado por ella.

ElTribunal Constitucional es un órgano jurisdiccional por su procedimiento de actuación y de adopción de decisiones y por su independencia de otros órganos constitucionales. No empece a esta calificación el que no esté encuadrado entre los órganos del Poder Judicial. El Tribunal, se ha dicho gráficamente, no es un árbitro llamado a dirimir contiendas según su leal saber y entender, sino un órgano constitucional de naturaleza jurisdiccional que tiene en el Derecho su instrumento y su límite. Tal naturaleza no contradice la politicidad de sus competencias. Como escribió García Pelayo, el Tribunal Constitucional participa en la función de dirección política y ejerce una acción reguladora del sistema político.

El Tribunal Constitucional es el intérprete supremo de la Constitución. Su Ley Orgánica así lo afirma en su artículo 1.1, en el que añade que, en cuanto tal, es independiente de los demás órganos constitucionales y está sometido únicamente a la Constitución y a dicha Ley Orgánica. Ser el supremo intérprete de la Constitución significa que tal interpretación no está sometida a revisión más que por sí mismo, ni siquiera por parte del Tribunal Europeo de Derechos Humanos, ni del Tribunal de Justicia de la Unión Europea, que no tienen competencias al respecto. Significa, pues, que el Tribunal Constitucional no está sometido a mejor parecer de ningún poder estatal y que todos, en cambio, están vinculados a él. Pero su suprema interpretación no puede consistir en cerrar el paso a las distintas opciones políticas que quepan en el marco de la Constitución.

En realidad, en el sistema español el Tribunal Constitucional no es el único juez de la constitucionalidad de las normas ni de los actos 
de los poderes públicos. Todo juez o tribunal lo es en su esfera, puesto que debe aplicar la Constitución, debe aplicar las demás normas interpretándolas conforme a aquélla y debe dejar de aplicarlas o elevar una cuestión de inconstitucionalidad al Tribunal Constitucional, según los casos, cuando no se da la conformidad de una norma cualquiera con la Constitución. Cabe decir incluso que, dada la limitación material de las competencias del Tribunal Constitucional, la interpretación que hace el Tribunal Supremo en el ejercicio ordinario de su actividad es también suprema, salvo en materia de derechos fundamentales. Cuestión diferente es que, una vez el Tribunal Constitucional se haya pronunciado sobre un precepto de la norma suprema, esta interpretación se impone al Tribunal Supremo en su actuación futura, así como a todos los demás operadores jurídicos y políticos.

En fin, ser el supremo intérprete de la Constitución significa, además, como han escrito F. Rubio Llorente y M. Aragón, que el carácter vinculante de su interpretación se extiende a la que hace de otras normas distintas, tanto de las que integran el bloque de la constitucionalidad cuanto de las demás normas legales objeto de su control. Así sucede cuando el Tribunal dicta una sentencia interpretativa, esto es, una sentencia que excluye algunas posibles interpretaciones de la ley enjuiciada como contrarias a la Constitución, o las excluye todas menos una, vinculando siempre en esta interpretación a los demás poderes públicos. En este cometido, dice F. Rubio Llorente, el Tribunal Constitucional es algo más que el legislador negativo kelseniano, pues su interpretación se incorpora a la ley, desapareciendo la libertad interpretativa del juez ordinario y de los demás poderes públicos. En estos casos, no estamos, por consiguiente, ante una actividad nomofiláctica, sino propiamente nomotética, ante una fuente del derecho del mismo rango que la ley.

\section{COMPOSICIÓN, ORGANIZACIÓN INTERNA Y FUNCIONAMIENTO}

El constituyente buscó configurar un órgano que respondiera, en términos generales, a las corrientes de opinión existentes en el país, pero que, al mismo tiempo, preservara su independencia. Se pretendió igualmente dotarlo de estabilidad sin impedir su renovación temporal, y se ha querido evitar la funcionarización y corporativización de sus miembros tanto como el nombramiento de personas de acentuada significación política. De ahí la exigencia de que tales miembros sean juristas de reconocida competencia con más de quince años de 
antigüedad. Y de ahí también el procedimiento de su nombramiento: cuatro por el Congreso de los Diputados, con una mayoría de tres quintos de la Cámara, cuatro por el Senado con igual mayoría, dos por el Gobierno y dos por el Consejo General del Poder Judicial. En total, doce, número par, que quizá no haya sido la opción más conveniente.

La misma línea de independencia persiguen los demás elementos de dicho estatuto jurídico, coincidente, en unos aspectos, con el de los parlamentarios, $y$, en otros, con el de los jueces: incompatibilidades, inamovilidad, inviolabilidad por las opiniones expresadas en el ejercicio de su cargo y fuero especial en causas criminales (la Sala de lo Penal del Tribunal Supremo).

El Tribunal goza de autonomía reglamentaria, lo mismo que las Cámaras legislativas, con la diferencia de que su organización y funcionamiento está heterónomamente establecida por su Ley Orgánica, en tanto que las Cámaras proveen a ello en su propio reglamento autónomamente establecido. Dicha Ley Orgánica ha dispuesto la constitución de dos salas, compuestas cada una por seis magistrados, y el funcionamiento del Tribunal será, según los casos, en Pleno, en dichas salas o en las secciones de aquél y de éstas que se constituyan; habitualmente funcionan dos secciones de tres miembros en cada Sala.

Es necesario el conocimiento del Pleno en los recursos y en las cuestiones de inconstitucionalidad, además de en los conflictos constitucionales. Los recursos de amparo son sustanciados, salvo excepción, ante las salas. Y las secciones realizan el despacho ordinario $Y$ deciden sobre la admisibilidad de los recursos; desde 1988, la inadmisión de los recursos de amparo (no los de inconstitucionalidad) puede decidirse por providencia de un solo magistrado, con lo que se pretende aligerar el trabajo del Tribunal. No obstante, el Pleno siempre puede recabar para sí, en cada caso, las competencias atribuidas a estos órganos internos.

El Presidente goza de voto de calidad para dirimir los empates en las votaciones, prerrogativa de no desdeñable importancia, como la práctica ha demostrado por ser par el número de miembros delTribunal y de las salas. El Vicepresidente sustituye al Presidente cuando sea preciso y, como Presidente de la Sala $2 .^{a}$, goza también de voto de calidad.

Existe un GabineteTécnico del Presidente y una Junta de Gobierno, creados por el Reglamento de organización del Tribunal. Éste está asistido por letrados, uno de los cuales es nombrado Secretario General del Tribunal. 


\section{COMPETENCIAS}

Las competencias del Tribunal Constitucional pueden ser sintetizadas del modo siguiente:

a) Competencias internas o sobre el ejercicio de su propia jurisdicción:

1. Es el único órgano constitucional que tiene competencia para decidir sobre sus propias competencias.

2. Decide libremente sobre la admisión de recursos $y$ cuestiones constitucionales $y$, posteriormente, tiene gran autonomía para decidir el curso del proceso.

3. Tiene autonomía reglamentaria y presupuestaria.

4. Elige a sus propias autoridades y decide sobre el cese o suspensión de sus miembros.

b) Competencia de control de constitucionalidad de las leyes $y$ normas con rango, valor o fuerza de ley:

1. Resolución de los recursos de inconstitucionalidad.

2. Resolución de las cuestiones de inconstitucionalidad.

3. Declaración sobre la constitucionalidad del texto de los tratados antes de serles prestado el consentimiento estatal.

c) Competencia sobre el ejercicio de competencias por parte de otros poderes públicos (resolución de los conflictos constitucionales):

1. Resolución de los conflictos de competencias

2. Resolución de los conflictos entre órganos constitucionales.

d) Competencia sobre la protección de los derechos fundamentales y libertades públicas: resolución de los recursos de amparo.

Del recurso de amparo se habla en otra colaboración de este mismo número, a la que remito. A las competencias internas me he referido brevemente en el epígrafe anterior. A continuación haré alusión, muy sumariamente, a las demás del anterior esquema. 


\section{CONTROL DE LA CONSTITUCIONALIDAD DE LAS LEYES Y DE LAS NORMAS DEL MISMO RANGO}

\subsection{Normas impugnables}

La relación de normas impugnables que hace el artículo 27.2 de la Ley Orgánica delTribunal no es sino como un desarrollo de lo preceptuado por el artículo 161.1.a de la Constitución. En su virtud, las normas susceptibles de declaración de inconstitucionalidad son:

a) Las leyes, tanto de Cortes como autonómicas, así ordinarias como orgánicas; $y$, por tanto, también los estatutos de autonomia.

b) Las disposiciones normativas de poder central y de las Comunidades Autónomas con fuerza, rango o valor de ley, concepto en el que debemos incluir los decretos-leyes y los decretos legislativos.

c) Los tratados internacionales.

d) Los reglamentos parlamentarios, sean de las Cortes, o de cualquiera de sus Cámaras, sean autonómicos; también, según el Tribunal Constitucional, el Estatuto del Personal de las Cortes Generales, norma que, aunque de clara naturaleza reglamentaria, tiene valor y fuerza de ley.

Doctrinalmente debe sostenerse que los actos del poder central o de los poderes autonómicos con fuerza de ley deben ser incluidos en esta relación. Remito al epígrafe octavo de este trabajo.

\subsection{Bloque y canon de la constitucionalidad}

El artículo 28.1 de la Ley Orgánica del Tribunal precisa que la conformidad o disconformidad de las referidas normas con la Constitución se apreciará considerando, además de los preceptos constitucionales, las leyes que delimiten las competencias del Estado (poder central y de las Comunidades Autónomas), o que regulen o armonicen el ejercicio de las competencias de estas últimas, así como las que regulan el procedimiento de producción de normas con rango de ley. Todo este conjunto normativo constituye el bloque de la constitucionalidad. Por su parte, se conoce como canon o parámetro de la constitucionalidad de un precepto legal las normas que el Tri- 
bunal utiliza en cada caso para apreciar la constitucionalidad del precepto «juzgado».

Así, pues, las normas que integran el bloque de la constitucionalidad son, además del propio texto fundamental, las siguientes:

a) Los estatutos de autonomía, las leyes marco, las de armonización y las de delegación y de transferencia de competencias.

b) Las leyes que contengan delegaciones legislativas.

c) Los reglamentos parlamentarios, tanto centrales como autonómicos, a pesar del silencio de la Ley Orgánica. Así debe ser interpretado y así lo ha sido por el Tribunal, si bien no todos sus preceptos forman parte de este elenco, sino sólo los que tienen incidencia en el procedimiento legislativo'.

d) El artículo 28.2 de la Ley Orgánica hace una confusa referencia a la relación entre la ley orgánica y la ordinaria, conforme al cual la primera puede nutrir el canon de la constitucionalidad de la segunda, tanto por el procedimiento seguido en su aprobación como por la materia regulada.

Pero, en realidad, como dicen F. Balaguer y A. García Martínez, el canon de la constitucionalidad lo construye en cada caso el Tribunal Constitucional con su selección de las normas citadas y con la interpretación que hace de ellas. En el bien entendido de que las normas utilizadas por el Tribunal en cada caso son las vigentes en el momento en que ejerce el control, no las que lo estuvieran cuando la norma «juzgada» fue aprobada.

\subsection{Tipos de control de constitucionalidad}

Los tipos de control existentes en el Derecho comparado obedecen fundamentalmente a tres criterios: el momento en que se realiza, el procedimiento utilizado y el aspecto que se enjuicia. Conforme al primero, el control puede ser reparador, también llamado sucesivo y represivo, que tiene lugar una vez promulgada la norma, o bien previo o preventivo, que se realiza antes de su promulgación y, por tanto no enjuicia propiamente una norma, sino sólo un proyecto.

1 STC 36/1990, de 1 de marzo. Cfr. ATC 23/1986. 
A su vez, el control, sucesivo puede ser instado por vía de acción o por vía de excepción. En el primer caso estamos ante el tipo más usual de control: el recurso de inconstitucionalidad. La segunda vía constituye la denominada cuestión de inconstitucionalidad. Históricamente, el recurso era propio de la jurisdicción constitucional concentrada, mientras que la cuestión se daba en la jurisdicción difusa. Pero el Derecho comparado ha evolucionado acercando los dos sistemas, evolución a la que responde la Constitución española admitiendo ambos tipos de control.

Desde el punto de vista del aspecto de la norma cuya constitucionalidad se considera, el control puede ser formal o material. El formal enjuicia si el procedimiento seguido en la producción normativa es el establecido en la Constitución y/o, en su caso, por las demás normas que regulan dicho procedimiento, principalmente los reglamentos parlamentarios, pero no sólo ellos. El control material aprecia la conformidad o disconformidad del contenido de la norma examinada con los preceptos del bloque de la constitucionalidad.

\subsection{Recurso de inconstitucionalidad}

Ciñéndonos a los aspectos menos conocidos por el público en general, pero sin obviar algún dato básico, podemos reducir nuestra exposición diciendo que el procedimiento a seguir en este recurso viene establecido en la Ley Orgánica delTribunal Constitucional y que éste ha adoptado desde el principio un notable antiformalismo (sólo levemente corregido con posterioridad), interpretando flexiblemente su propia Ley Orgánica, a fin de que las acciones ejercidas con tal propósito lleguen, siempre que sea posible, a término, esto es, a sentencia; todo ello en beneficio de la depuración constitucional del Ordenamiento jurídico.

La sucesión de normas en el tiempo suscita problemas del máximo interés sobre los que el Tribunal ha establecido jurisprudencia:

a) La promulgación de una ley que sustituye a un decreto-ley recurrido de inconstitucionalidad no priva de objeto al recurso, puesto que persiste el interés objetivo de velar por la corrección del sistema de producción normativa.

b) La derogación o modificación de una ley recurrida y sin ultraactividad (esto es: que no prolonga sus efectos en el tiempo) puede eliminar el objeto del recurso si éste versa sobre los preceptos derogados o modificados, o bien reducirlo a 
los preceptos que permanecen vigentes. Esto fue lo ocurrido en materia de objeción de conciencia con la modificación de la Ley de 1984 y del Código Penal por la Ley Orgánica 14/19852; lo mismo puede ocurrir con la modificación de la Ley Orgánica $8 / 2000$, sobre extranjeria, por la que en los momentos de redactar estas páginas está en curso de aprobación ${ }^{3}$.

c) Con mayor razón, si es una ley autonómica la recurrida y suspendida (lo que no ocurre con las normas generales de los poderes centrales), y no ha producido efectos jurídicos, su derogación durante el proceso de inconstitucionalidad priva a éste de todo objeto y provoca su extinción 4 .

d) En fin, si durante la tramitación de un recurso cambia la norma básica estatal-central que ha de desarrollar la(s) Comunidad(es) Autónoma(s), el recurso puede quedarse sin objeto, a no ser que la colisión siga presentándose con la norma nueva. Así aconteció con la promulgación de la Ley Orgánica del Derecho a la Educación (LODE), que modificó sustancialmente las bases contenidas en la anterior Ley Orgánica del Estatuto de Centros Escolares (LOECE) 5 .

\subsection{Cuestión de inconstitucionalidad}

Con el mismo tono de contención propio de este número monográfico, resaltaremos únicamente algunos aspectos del referido instituto.

La Constitución española está más próxima en este asunto a la alemana, en la que sólo el juez puede plantear esta cuestión ante el Tribunal Constitucional Federal, que a la italiana, en la que las partes y el Ministerio Fiscal tienen un mayor protagonismo, y más cerca también del sistema segundorrepublicano español, en el que toda cuestión pasaba por el filtro del Tribunal Supremo.

2 SSTC 76/1983, de 2 de diciembre, y 60/1986, de 25 de mayo.

3 SSTC 160 y 199/1987, de 22 de octubre y 16 de diciembre, y 212/1996, de 19 de diciembre.

4 ATC $349 / 1985$, de 23 de mayo.

5 STC 137/1986, de 6 de noviembre, 
De esta manera se establece una colaboración entre los órganos judiciales y el Tribunal Constitucional. Tal colaboración, en mayor medida que el recurso, permite contrastar con la cambiante realidad social el contenido de las leyes ${ }^{6}$. Pero, como dice P. PérezTremps, junto a esa finalidad objetiva de depuración del Ordenamiento, la cuestión de inconstitucionalidad cumple una función de garantía de intereses subjetivos en el proceso a quo, pues éstos son la razón última de su planteamiento en muchas ocasiones.

El órgano judicial es, en principio, el competente para determinar cuáles son las normas aplicables al caso del que está conociendo. Por eso el Tribunal Constitucional admitirá las cuestiones que le plantee, salvo cuando falten las condiciones procesales o sean notoriamente infundadas (artículo 37.1 de la Ley Orgánica del Tribunal). Pero, de otro lado, el planteamiento de la cuestión está condicionado a que el órgano judicial considere de muy probable inconstitucionalidad la norma aplicable al caso y así lo razone en el juicio de relevancia que debe acompañar a la cuestión, en el cual debe argumentar suficientemente su imposibilidad de salvar la constitucionalidad de la ley por via interpretativa, además de exponer cómo su fallo depende de la validez o invalidez de la norma cuestionada 7 .

No estamos, por consiguiente, ante un derecho de las partes del litigio de origen que obligue al juez a promover la cuestión de que tratamos. Las partes se limitan a instarla y es el órgano judicial el que decide al respecto, si bien, ulteriormente, las partes que no se hayan visto atendidas en su petición, pueden recurrir en amparo por denegación de una tutela judicial efectiva.

Son muy pocas las cuestiones inadmitidas por el Tribunal Constitucional, pero, en caso de que asi sea, el órgano judicial puede volver a plantearla si lo considera procedente, aclarando los extremos defectuosos; si no lo hace, puede promoverla otro órgano judicial en una sucesiva instancia ${ }^{8}$.

El propio Tribunal Constitucional puede autoproponerse una cuestión de este tipo conforme al artículo 55.2 de su Ley Orgánica, en el supuesto de un recurso de amparo estimado contra la aplicación de una ley que lesiona derechos fundamentales. En tal caso la Sala ele-

6 SSTC 3,9 y 17/1981, de 2 de febrero, 31 de marzo y 1 de junio, etc.

7 SSTC 14 y 17/1981, de 29 de abril y 1 de junio; 126/1987, de 16 de julio, y 105/1988, de 8 de junio; ATC de 5-VII-1986.

8 STC 134/1987, de 21 de julio. 
vará la cuestión al Pleno para que resuelva en nueva sentencia. La particularidad principal de este modelo de cuestión consiste en que el recurso de amparo puede ultimarse y resolverse sin esperar la solución de la cuestión en el Pleno; es decir, no se trata, como en el instituto estudiado en líneas precedente, de una cuestión previa o incidental.

\subsection{Control de constitucionalidad de los tratados internacionales}

En el Ordenamiento español los tratados internacionales válidamente celebrados, una vez publicados oficialmente en España, integran el Ordenamiento interno, según el artículo 96.1 de la Constitución. Este precepto añade que sus disposiciones sólo pueden ser derogadas, modificadas o suspendidas en la forma prevista por los propios tratados o de acuerdo con las normas generales del Derecho Internacional. De otro lado, los tratados son susceptibles de control, de constitucionalidad, bien preventivo (artículo 95 constitucional), bien sucesivo (artículo 27.2 de la Ley Orgánica delTribunal). De donde se deduce que tienen rango de ley; éste, al menos, es mi parecer, sostenido desde hace veinte años; sin embargo, la cuestión es muy disputada y no conozco ningún internacionalista que la sostenga, incluso no todos los constitucionalistas lo hacen; pero tal problema no afecta al presente trabajo.

Si se ha controlado preventivamente, la declaración desfavorable respecto de la constitucionalidad del texto acordado abre cuatro posibilidades, según $A$. Remiro Brotóns: a) se vuelve a negociar el texto; b) se le hacen reservas, si en ello conviene la otra parte; c) se reforma la Constitución antes de prestar el consentimiento estatal al tratado (esto fue lo sucedido con ocasión de la ratificación del Tratado de Maastricht) 9 ; y d) se renuncia a su conclusión.

El tiempo hábil para instar la declaración del Tribunal Constitucional es el inmediatamente posterior a la autenticación del texto del tratado, es decir, cuando el texto esté definitivamente fijado y aún no haya recibido el consentimiento del Estado (requerir antes al Tribunal carecería de sentido, puesto que el texto todavía puede experimentar algún cambio).

El control sucesivo (recurso de inconstitucionalidad propiamente dichol puede intentarse dentro de los tres meses posteriores a la

9 Beclaración del Tribunal Constitucional de 1-VII-1992. 
publicación del tratado. Están facultados para instarlo quienes, en general, pueden hacerlo contra cualquier norma con rango o valor de ley (incluso los Gobiernos y Parlamentos autonómicos), pero parece inverosímil que lo haga el Presidente del Gobierno que ha negociado el tratado (sí cabe esa posibilidad si ha habido cambio gubernamental en el ínterin, lo que también parece difícil que suceda) y es improbable que lo haga el Defensor del Pueblo.

Si la sentencia confirma la inconstitucionalidad de alguna disposición del tratado, se produce una situación de Derecho internacional ciertamente delicada. De una parte, el Estado ha de hacer frente a sus responsabilidades internacionales de dos modos: directamente, respecto de las otras partes del tratado, e indirectamente, respecto de los ciudadanos de esos países que hubieran ultimado negocios jurídicos con los españoles (ciudadanos o Estado) con la cobertura jurídica del tratado en cuestión. También es responsable, por las mismas causas, ante las personas físicas y jurídicas españolas. De otra, los poderes públicos deben proceder a la renegociación, denuncia o suspensión del tratado por los procedimientos establecidos en éste o en las normas de Derecho internacional.

\subsection{La sentencia en el proceso de inconstitucionalidad}

Las sentencias pueden ser desestimatorias, estimatorias o interpretativas. Las primeras confirman la compatibilidad con la Constitución de la norma impugnada o cuestionada. Las estimatorias aprecian un vicio de inconstitucionalidad en la norma enjuiciada. Las interpretativas son formalmente desestimatorias, pues salvan la ley, pero, en parte, tienen un contenido materialmente estimatorio porque declaran inconstitucionales ciertas interpretaciones de la misma, o todas excepto una.

El fallo de la sentencia estimatoria tiene efectos desde la promulgación de la ley (ex nunc), desde la publicación de la sentencia (ex tunc) o proyectado sólo hacia el futuro. Sus efectos territoriales pueden ser generales (para todo el ámbito nacional) o parciales (para una o varias Comunidades Autónomas). Desde el ángulo de la validez de la norma estimada inconstitucional, la sentencia estimatoria puede comportar una declaración de nulidad de la misma, o solamente la de su inconstitucionalidad $\sin$ efectos anulatorios ${ }^{10}$. 
Es común a las sentencias delTribunal Constitucional tener valor de cosa juzgada, vincular a todos los poderes públicos y producir efectos generales frente a todos $y$ efectos para las partes. Son irrecurribles y se publican en el Boletín Oficial del Estado con los votos particulares discrepantes que haya habido, como se hace en el Tribunal Supremo de Estados Unidos y en el Tribunal Europeo de Derechos Humanos; también se ha extendido esta práctica en los tribunales españoles de la jurisdicción ordinaria.

Lo vinculante, al menos para los poderes públicos, es tanto el fallo como la motivación, que incorpora una interpretación del texto fundamental en sus fundamentos jurídicos. Por eso, la Ley Orgánica del Poder Judicial vincula a los jueces y tribunales a la interpretación de la Constitución hecha por el Tribunal Constitucional.

El Tribunal niega la constitucionalidad de las leyes meramente interpretativas de la Constitución. En cambio, él sí puede dictar sentencias interpretativas tanto de la Constitución como de las leyes y normas con rango de ley sometidas a su jurisdicción. El propio Tribunal justifica la emanación de estas sentencias, existente también en otros países, como un medio de salvar la norma legal hasta donde sea posible y evitar lagunas innecesarias en el Ordenamiento". Contemplado en esta perspectiva, el control de constitucionalidad, como dice J. Jiménez Campo, busca un equilibrio entre la garantía de la Constitución frente al legislador y la garantía de la propia ley, que debe seguir siendo tal en tanto no recaiga sobre ella un pronunciamiento expreso negativo.

\section{CONFLICTOS DE COMPETENCIAS}

EITribunal Constitucional tiene atribuida por el articulo 161.1.c la facultad de dirimir los conflictos de competencias entre los poderes centrales y las Comunidades Autónomas y los de éstas entre sí. Como las competencias básicas están atribuidas por el bloque de la constitucionalidad, todo conflicto de competencias termina siendo un proceso de constitucionalidad. Por eso se ha atribuido su conocimiento al Tribunal Constitucional y no a los tribunales ordinarios. El propio Tribunal Constitucional titubeó al principio a la hora de señalar la línea

11 STC 5/1981, de 13 de febrero; Cfr. SSTC 77/1985, de 27 de junio, y $341 / 1993$, de 18 de noviembre, entre otras muchas. 
fronteriza entre este tipo de conflictos y el recurso de inconstitucionalidad promovido por los mismos actores ${ }^{12}$, pero posteriormente los ha diferenciado ${ }^{13}$ : hay conflicto de competencias cuando los órganos se consideran igualmente competentes o incompetentes para proveer en un determinado asunto sin necesidad de cuestionar las normas en que el ente contrario apoya su competencia; por tanto, pueden dar lugar a su planteamiento normas de rango infralegal, lo que no es posible en un proceso de inconstitucionalidad; además, el juicio de inconstitucionalidad puede versar sobre cualquier materia, y no sólo sobre competencias.

Pero tampoco se descarta que la competencia controvertida esté atribuida por ley o norma de su rango o fuerza, en cuyo caso el conflicto es propiamente un juicio sobre la constitucionalidad de la misma. Por otra parte, el Tribunal suele acumular los conflictos de competencia y los recursos de inconstitucionalidad que versan sobre un mismo problema.

Los conflictos pueden ser positivos y negativos. Los positivos (que son casi la totalidad de ellos) existen cuando hay más de un pretendido titular de la competencia, aunque el órgano proponente no sea el que la recaba para sí, sino para depurar el orden competencial establecido. Estamos ante un cauce reparador, no preventivo. Por su parte, el Tribunal niega su competencia para conocer de los conflictos que se susciten entre los órganos centrales del Estado y cualesquiera otras entidades locales, incluidos los denominados Territorios Históricos del País Vasco ${ }^{14}$; la jurisdicción competente, en estos casos, es la ordinaria.

La Ley Orgánica asigna a la sentencia un posible doble contenido: declarar la titularidad de la competencia controvertida y acordar, en su caso, la anulación de la disposición o acto motivo del conflicto, así como lo que fuere procedente respecto de las situaciones creadas a su amparo. La sentencia vincula a todos los poderes públicos y tiene efectos frente a todos, desapareciendo el carácter controvertido de la competencia.

Existe conflicto negativo cuando los órganos centrales del Estado y los de la Comunidad Autónoma declinan su competencia y omiten toda actuación sobre determinada materia al serle instada por cual-

12 SSTC 25 y 32/1981, de 14 y 28 de julio.

13 Cfr., por todas, STC 50/90, de 29 de marzo.

14 STC 11/1984, de 2 de febrero. 
quier persona. Es el administrado el que, agotados todos los trámites, está legitimado para promover el conflicto ante el Tribunal Constitucional. La Ley Orgánica sólo prevé la existencia de conflictos negativos entre las Administraciones estatal (central) y autonómica. Se trata, por tanto, de actos administrativos. La sentencia declarará cuál es la Administración competente.

\section{IMPUGNACIÓN POR EL GOBIERNO DE LAS DISPOSICIONES SIN FUERZA DE LEYY RESOLUCIONES DE LAS COMUNIDADES AUTÓNOMAS}

El Título V de la Ley Orgánica regula estas impugnaciones, que, por exclusión, hemos de entender que se refieren a la actividad administrativa autonómica con vicio de inconstitucionalidad (de lo contrario, el juez competente sería el ordinario). Se trata, como dice R. Punset, de un dispositivo de cierre de todo el sistema impugnatorio. Por esta vía fueron impugnados, en su día, un convenio suscrito por los Presidentes de Cataluña y Murcia y una resolución del Presidente del Parlamento de Navarra proponiendo al Rey el nombramiento de Presidente del Gobierno autonómico ${ }^{15}$. ElTribunal debe proceder a la suspensión de la disposición, resolución o acto autonómico, suspensión que deberá mantener o levantar si no dicta sentencia dentro de los cinco meses siguientes a la iniciación del procedimiento.

\section{CONFLICTOS ENTRE ÓRGANOS CONSTITUCIONALES}

Ésta es otra competencia atribuida al Tribunal por su Ley Orgánica, no por la Constitución. Se trata, dice el Tribunal, de un especialísimo proceso que tiene como principal objeto la vindicación de una competencia por parte de un órgano constitucional, con lo cual se busca preservar el tradicional principio de división de poderes entre los órganos constitucionales (centrales y generales) del Estado ${ }^{16}$.

Los órganos que pueden promoverlos, según la Ley Orgánica, son el Gobierno, el Congreso de los Diputados, el Senado y el Consejo General del Poder Judicial. La Ley Orgánica del Tribunal de Cuentas

15 SSTC 44/1986, de 17 de abril, y 16/1984, de 6 de febrero.

16 STC 45/1986, de 17 de abril. 
añadió este órgano a la anterior relación. No está incluida, por razones obvias, la Corona, ni tampoco el propio Tribunal Constitucional, pues es él quien decide sobre las competencias de los demás órganos y sobre la suya misma. Este elenco de órganos habilitados no deja de presentar dificultades de interpretación, que veremos en un epígrafe posterior.

Sólo ha habido hasta ahora tres conflictos de este tipo, resueltos en una misma sentencia ${ }^{17}$.

\section{QUAESTIONES DISPUTATAE}

\subsection{Sobre los actos con fuerza de ley susceptibles de recurso}

Ya dijimos en un epígrafe anterior que nos ocupariamos en éste de exponer qué actos de los poderes centrales o autonómicos son susceptibles de control de constitucionalidad por tener fuerza de ley. En esta categoría hay que incluir:

1. La autorización parlamentaria de tratados que no se haga por ley orgánica.

2. La convalidación de los decretos-leyes.

3. Las declaraciones de los estados de excepción y sitio.

4. La autorización de la prórroga de los estados de alarma y excepción.

5. La adopción de medidas coercitivas o de intervención del poder central respecto de las Comunidades Autónomas.

6. Los actos de las Cortes Generales en sesión conjunta relativos a la Corona: provisión, en su caso, de la sucesión, de la Regencia y de la tutela del Rey menor; y reconocimiento de la inhabilitación del Rey para ejercer la Jefatura del Estado.

La relación de todos estos actos es elaboración de la doctrina, que, sin embargo, no es pacífica respecto de todos ellos. A mi juicio, todos los enunciados deben estar en ella por tener fuerza de ley. Pero todavía no ha llegado al Tribunal ningún caso relativo a dichos actos, por lo que éste no ha tenido oportunidad de pronunciarse sobre ellos.

17 Misma Sentencia. 


\subsection{Control de constitucionalidad de los tratados}

Conforme con el artículo 96 de la Constitución, los tratados, una vez incorporados al Ordenamiento interno, sólo pueden ser modificados por el procedimiento expresado en ellos mismos o por las normas generales del Derecho internacional. ¿Cómo se los va a invalidar entonces por sentencia del Tribunal Constitucional? Esta objeción es salvable si entendemos, con A. Remiro Brotóns, que lo dicho por tal precepto constitucional reza sólo para los tratados válidamente celebrados, lo que no se puede decir de los inconstitucionales. Los tratados que contengan disposiciones contrarias a la Constitución habrian necesitado, para ser válidos, de una previa reforma constitucional que estableciera la conformidad entre ambos textos, según dispone el articulo 95 de nuestra norma suprema.

Como vemos, la complejidad de la situación es tal que siempre será preferible agotar las posibilidades de salvar las discrepancias entre el tratado y la Constitución mediante una sentencia interpretativa.

\subsection{Relación de la Constitución española con el Derecho comunitario y con los tratados internacionales}

ElTribunal Constitucional tiene establecido que el Derecho comunitario no forma parte del bloque de la constitucionalidad. De manera que la eventual vulneración del mismo por una norma española con rango de ley no puede ser cuestionada ni recurrida por inconstitucionalidad; es, dice, una cuestión infraconstitucional en la que lo procedente es un reenvío prejudicial ante el Tribunal de Justicia de la Unión Europea. Lo mismo puede decirse respecto de una hipotética vulneración de un tratado internacional, con la diferencia de que no cabe el procedimiento del reenvio.

En realidad, si la norma de Derecho comunitario o del tratado internacional es posterior a la ley nacional, hay que entender que derogan o modifican ésta en lo necesario para tener plena eficacia. $Y$, si es anterior, los poderes públicos españoles no pueden producir una norma que la contradiga. Aun así, la fricción puede darse, pero la vía de solución del problema no es la jurisdicción constitucional. No obstante, por lo que se refiere al Derecho comunitario, los Tribunales Constitucionales alemán e italiano no son tan rígidos como el español y últimamente lo incorporan al bloque de la constitucionalidad. A mi juicio, 
en España debería hacerse lo mismo, como sostiene C. Vidal, por cuanto el Derecho comunitario es Derecho vigente que desplaza la aplicación de una norma de producción interna y el juez que aplique esta última con preferencia a aquél, no está produciendo una resolución conforme a Derecho, que es lo que demanda el derecho fundamental a la tutela judicial efectiva (artículo 24.1 de la Constitución).

De otro lado, como sabemos, los tratados internacionales son susceptibles de control de constitucionalidad. Ahora bien, el control preventivo de los mismos no equivale realmente a un recurso, puesto que, en tanto el tratado no se perfeccione y se publique, no integra el Ordenamiento jurídico español y una estimación de su inconstitucionalidad no puede comportar su anulación, ya que todavía no es norma española. Por eso la Constitución no habla en estos casos de recurso, sino de requerimiento al Tribunal Constitucional, y de declaración de éste, no de sentencia, si bien la Ley Orgánica habla, erróneamente a mi entender, de fallo. Según el propio Tribunal, tal declaración no es un dictamen, sino una resolución.

\subsection{La autocuestión de inconstitucionalidad}

Ya hemos indicado que la Ley Orgánica (artículo 55.2) da por supuesto que el recurso de amparo, en cuyo desenvolvimiento se plantea la autocuestión de inconstitucionalidad ha sido estimado. Precepto criticable ciertamente, puesto que, si el amparo se otorga porque la ley es lesiva de un derecho fundamental, no es que el Pleno del Tribunal pueda declarar su inconstitucionalidad, sino que debe de hacerlo. Una regulación más acertada, como propone J. Oliver, habría sido su tratamiento como cuestión previa, suspendiendo la Sala la sentencia en el recurso de amparo hasta el pronunciamiento del Pleno sobre la cuestión de inconstitucionalidad; o, como apunta L. López Guerra, que el Pleno avoque para sí la resolución del recurso de amparo. Con cualquiera de estas fórmulas, ni el Pleno se vería mediatizado por una Sala, ni se correría el riesgo de sentencias discrepantes, como ha ocurrido en alguna ocasión.

\subsection{Carácter constitutivo o declarativo de las sentencias. Sentencias interpretativas}

La regulación que hace la Constitución de los efectos de las sentencias es muy imprecisa. Por eso, el Tribunal prefiere apoyarse 
en su propia Ley Orgánica, la cual, pese a todo, tampoco despeja con claridad algunas incógnitas. La doctrina, en general, se inclina por considerar que el vicio de inconstitucionalidad se produce en origen y es insubsanable, limitándose la sentencia a declararlo. Estimación que se ve corroborada por la Constitución y la Ley Orgánica cuando dicen que el Tribunal, al declarar la inconstitucionalidad de una ley, declarará también su nulidad. Es decir, la sentencia tendría carácter declarativo, no constitutivo de esa inconstitucionalidad y nulidad.

ElTribunal se inclinó en un principio hacia esta posición. No obstante, surgieron excepciones no previstas en la defectuosa regulación de la materia:

a) Una ley aprobada como orgánica pero que versa sobre materia no reservada a este procedimiento legislativo no debe ser expulsada del Ordenamiento, sino sólo privada del carácter orgánico. Aquí, inconstitucionalidad no equivale a nulidad.

b) Una ley de Cortes Generales que invade la competencia legislativa de una o de varias Comunidades Autónomas, debe ser declarada inconstitucional exclusivamente en cuanto afecta a esas Comunidades, circunscribiéndose su nulidad a dicho ámbito territorial.

De otra parte, como dice J. Santamaría, si el vicio no se declara, es como si no existiera. Por eso J. Almagro y P. Saavedra, eclécticamente, hablan del carácter declarartivo-constitutivo de las sentencias, lo que no sé si aclara algo el problema. Por su parte, el Tribunal ha matizado posteriormente su posición. De un lado, afirma que los preceptos declarados inconstitucionales no pueden ser aplicados desde el momento en que la sentencia es publicada en el Boletín Oficial del Estado. Pero también sostiene, frente a la tesis de la ineficacia originaria, que es él mismo quien tiene que apreciar en cada caso los efectos de la nulidad en relación con el pasado18; en algún caso, el Tribunal ha negado efectos retroactivos a la declaración de nulidad para no producir un vacío normativo en el Ordenamiento.

18 STC 45/1989, de 20 de febrero. 


\subsection{Conflictos de competencias}

El indice de conflictividad competencial en España es muy elevado, más que en Alemania y en Italia, salvo en los periodos (1993-1996 y 1996-2000) en que hubo acuerdos de legislatura entre los Gobiernos centrales y las fuerzas políticas nacionalistas. Esto significa, entre otras cosas, que se han endosado al Tribunal Constitucional problemas políticos que las fuerzas políticas no han sabido, podido o querido solucionar en la sede propia, la parlamentaria, o antes aún, en el diálogo político entre ellas. Esto mismo ha ocurrido en otros ámbitos.

\subsection{Relación de órganos legitimados para promover un conflicto entre órganos constitucionales}

Tal como ha quedado establecida la relación de órganos legitjmados para promover conflictos constitucionales, se percibe que el Poder Judicial queda tratado de forma desigual, puesto que su Consejo General no es Poder Judicial, sino el órgano de gobierno de éste, sin que tenga carácter representativo de los jueces y magistrados; por eso, dice el Tribunal Constitucional que este Consejo sólo puede promover conflictos referentes a sus competencias, no a las de los jueces. Con lo que éstos quedan inermes ante una injerencia, nada inimaginable, de las Cámaras legislativas, sobre todo de las Comisiones de Investigación.

De otro lado, tampoco se menciona a las Cortes Generales como órgano conjunto con competencias propias. Es una laguna que debía colmarse en el aún pendiente reglamento de las Cortes Generales. Mientras no sea así, tiene razón P. Tenorio cuando sostiene que la ley no puede ser objeto de conflicto, aunque debería serlo.

Añádase que, aunque la Ley Orgánica del Tribunal de Cuentas incluye a dicho órgano como legitimado para promover estos conflictos, es difícil concebir que se lo plantee a las Cámaras, porque esteTribunal es un órgano delegado de las Cortes. ElTribunal Constitucional ha zanjado la cuestión en el sentido de que los únicos órganos legitimados son los cuatro mencionados en su propia Ley Orgánica, con lo que corrige, sin descalificarla como inconstitucional, la Ley Orgánica del Tribunal de Cuentas.

En fin, otra grave laguna reside en que no se regulan los conflictos negativos, tan posibles como los positivos en este ámbito; piénsese, como dice P. Tenorio por vía de ejemplo, en la negativa del 
Ministro de Justicia a refrendar un nombramiento propuesto por el Consejo General del Poder Judicial.

\section{BALANCE}

\subsection{Labor del Tribunal en relación con los derechos fundamentales y con el Estado autonómico}

No hay comentarista que no elogie, en términos generales, la labor del Tribunal Constitucional en relación con los derechos fundamentales. Se ha sumado a la posición garantista de la Constitución e incluso la ha incrementado con su antiformalismo procesal, que ha cambiado, a su vez, los modos de la Administración de Justicia. Ha hecho del artículo 24 de la Constitución (tutela judicial efectiva de los derechos) el filtro por el que debe pasar el examen de toda limitación y presunta vulneración de los mismos. $Y$ ha construido con el artículo 23.1 un macroderecho, en el que, partiendo del derecho de participación política directamente o por medio de representantes, ha dado entrada al ejercicio que éstos hacen de su función representativa, en contra, a veces, de disposiciones de los órganos en que se integran (Ayuntamientos, Diputaciones, Parlamentos autonómicos, Congreso y Senado). Incluso ha dado entrada entre los derechos amparables a al-

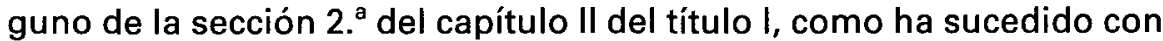
los del artículo 37 (derecho a la negociación colectiva laboral y a adoptar medidas de conflicto colectivo), los cuales se han visto (a mi entender, muy correctamente) conectados con el derecho a la libertad y a la acción sindical, que reconoce el artículo 28 y sí goza de la garantía del amparo.

No faltan lagunas en su quehacer, como las sentencias recaídas sobre el decreto-ley de expropiación de RUMASA, sobre la ley despenalizadora de ciertos supuestos de interrupción del embarazo o sobre la preferencia del varón sobre la mujer en la sucesión de los títulos nobiliarios, por poner sólo unos ejemplos. Pero el recurso de amparo se ha manifestado como una auténtica revolución en la eficacia inmediata de los derechos y en la vinculación de los poderes públicos a ellos. Su influencia en el tratamiento de los mismos por parte de estos poderes, y específicamente por parte del Poder Judicial, ha sido enorme y positiva.

Más ingente aún ha sido su tarea de poner orden en el caos del título VIII de la Constitución que pone las bases del Estado autonómico. Este título, técnicamente muy complicado, ha sido analizado y reor- 
denado por el Tribunal a través de una muy paciente jurisprudencia, en la que pueden detectarse, sí, unas etapas más centralistas y otras más autonomistas, pero que, en general, ha hecho legible nuestra organización territorial. Por eso, algún autor, como M. Aragón, ha calificado muy oportunamente nuestro modelo territorial como Estado jurisprudencialmente autonómico.

En fin, en su jurisprudencia electoral, garantista, como no podia ser menos, pueden percibirse deficiencias técnicas, acaso debidas a la precipitación, en las que la doctrina no ha reparado suficientemente ${ }^{19}$.

\subsection{Composición del Tribunal}

Respecto de las cautelas que el constituyente tomó a la hora de diseñar su composición, hay que reconocer que no impiden que una fuerza política que tenga mayoría absoluta en las Cámaras y, por tanto, esté en el ejercicio del Gobierno, y dado que, además, tal fuerza tiene la llave de la composición del Consejo General del Poder Judicial (órgano designante de dos magistrados del Tribunal) tenga amplias bazas para conformar una mayoría en éste. De ahí que se estableciera otro elemento más en el estatus de sus miembros, a saber, su mandato de nueve años (mandato superior incluso a dos legislaturas) y su renovación por terceras partes cada tres. Pero la mencionada renovación periódica parcial permite que el Gobierno y la fuerza política que lo apoya vaya conformando la composición del Tribunal, sobre todo si, como hasta ahora ha sucedido, repite su mayoría parlamentaria al menos en dos legislaturas. Se ha visto claramente en diversas ocasiones y se verá en marzo próximo cuando corresponda al Gobierno designar dos magistrados y al Consejo General del Poder Judicial a otros dos; el pronóstico es el de que, al menos, tres magistrados serán nombrados a gusto de la fuerza política mayoritaria y uno por la oposición. No es ése el mejor camino para conseguir un Tribunal que responda efectivamente a las corrientes de opinión, en plural, de la ciudadanía española

Esto ha determinado una cierta deriva política delTribunal, principalmente detectable en los periodos en los que los Gobiernos tenían

19 Cfr. el trabajo «Jurisprudencia del Tribunal Constitucional en materia electoral. Acotaciones críticas", que publiqué con Álvaro LóPEZ MiRA en el número 41 de esta Revista (Madrid, 1996), en el que mostramos algunas discrepancias de bulto. 
o tienen mayoría absoluta, con lo que su prestigio y auctoritas ha sufrido algún altibajo, coincidiendo con sentencias políticamente delicadas y en las que el Tribunal parece que ha sido receptivo de las posiciones gubernamentales o ha asumido una función política más allá de lo que le permiten la Constitución y su Ley Orgánica, función ni siquiera homologable a sentencias interpretativas.

\subsection{Diferencias entre las salas}

La organización interna del Tribunal, y de su trabajo, descrita en un epígrafe anterior, es funcional, pero, sobre no haber podido solucionar el problema del atasco de los asuntos que le llegan y, por tanto, el de la rapidez de su solución, presenta otro inconveniente, a saber, el de las posibles - y de vez en cuando reales - diferencias de criterio entre las dos salas o entre las cuatro secciones (por no hablar de las que puedan presentarse entre los doce magistrados cuando dictan providencias de inadmisión). Por eso, algún autor, como J. Arozamena, ha sostenido que no sería desacertado establecer una fórmula de coordinación entre ellas, elevando sus diferencias a un órgano superior (las secciones, a su Sala; las salas, al Pleno), para que éste resuelva decidiendo el criterio a seguir.

\subsection{Control de constitucionalidad de los proyectos de reforma constitucional}

He aquí un asunto prácticamente inédito, salvo la Declaración de 1-VII-1992 sobre el Tratado de Maastricht, pero que en el futuro habrá que abordar porque alguna vez tendrá que reformarse nuestro texto fundamental.

La generalidad de la doctrina se muestra proclive a admitir la impugnabilidad de tales reformas por catalogarlas como leyes de reforma. Mi parecer es contrario: antes de ser aprobadas, son meros proyectos o proposiciones de reformas constitucionales ( $y$ así se la ha llamado en la única ocasión en que ha tenido lugar; $y$, una vez aprobadas, son Constitución, $y$, por tanto, elTribunal no puede pronunciarse sobre ella, sino sólo acatarla. Estamos, pues, ante una laguna importante, que debería ser colmada (dicho sea como propuesta de lege ferenda) mediante el establecimiento de un control previo de los proyectos $y$ proposiciones de reforma constitucional, similar al que existe sobre los tratados internacionales. 